ESCOM

PD3 017

\title{
Some observations on classical QSAR
}

\author{
John G. Topliss \\ Department of Medicinal Chemistry, College of Pharmacy, University of Michigan, Ann Arbor, MI 48109-1065, U.S.A.
}

\author{
Received 24 August 1993 \\ Accepted 10 September 1993
}

Key words: QSAR; Hansch method; Free-Wilson method; Central nervous system penetration; Potency optimization; Bioisosterism; Receptor mapping; Synthesis termination

\section{SUMMARY}

Classical QSAR began almost 30 years ago. This article briefly traces its development, use and impact in relation to drug design and medicinal chemistry. Particular aspects discussed include hydrophobicity, relative potency in a series, tissue selectivity, central nervous system penetration, pharmacokinetics, potency optimization, bioisosterism, mechanistic insights, synthesis termination, receptor mapping, and the design of marketed drugs and late-stage drug candidates. In addition, some recent QSAR studies and examples of the use of the Free-Wilson approach are reviewed.

\section{INTRODUCTION}

The field of classical Quantitative Structure-Activity Relationships (QSARs) as we know it today began with the seminal work of Hansch and Fujita [1], published in 1964, which related biological activity for members of a congeneric series with substituent parameters representing hydrophobic, electronic and steric effects by means of an equation now known as the Hansch equation:

$$
\log (1 / C)=a \pi-b \pi^{2}+c \sigma+d E_{s}+k
$$

or

$$
\log (1 / C)=a \log P-b(\log P)^{2}+c \sigma+d E_{s}+k
$$

where $C$ is the concentration of a compound which produces a standard biological response, $\Pi$ is a hydrophobic substituent constant derived from partition coefficient data, $\sigma$ is the Hammett electronic substituent constant, $\mathrm{E}_{\mathrm{s}}$ is the Taft steric substituent constant and $\mathrm{P}$ is the octanol $-1 /$ water partition coefficient.

Prior to this, medicinal chemists considered structure-activity relationships only in qualitative descriptive terms and hydrophobicity received little attention. The breakthrough provided by the 
work of Hansch and Fujita which progressively brought about a pronounced change in the thinking about structure-activity relationships, was (i) the recognition of the impact of hydrophobicity and its quantitative expression in substituent parameter form and (ii) the concept that a combination of hydrophobic, electronic and steric effects would control activity and that their relative contributions could be determined by multiple regression analysis of a dataset from a congeneric series.

Also in 1964, the Free-Wilson method [2] was published and subsequently modified by Fujita and Ban [3] to the form in which it is now generally used. Later a hybrid Hansch/Free-Wilson method was formalized by Kubinyi [4] and nonstatistical methods were introduced by Topliss $[5,6]$. A detailed review of these methods and their origins is beyond the scope of this article, but excellent detailed accounts have been published [7-9].

\section{IMPACT OF QSAR}

Over the three decades following the birth of QSAR its concepts have been validated through the establishment of literally thousands of equations, accounting satisfactorily for quantitative relative activity in a series of compounds in terms of readily understandable physicochemical phenomena. This has been done across an immense variety of biological systems and compound types and has led to marked advances in medicinal chemistry and drug design [10]. It has also been used quite extensively in the agrochemical and environmental toxicology fields.

QSAR represents an important stage in the development of our understanding of the fundamentals of the processes and factors controlling drug action, including the role of hydrophobicity [11], and has provided many useful insights for drug design [12]. Many successful activity predictions have been made from QSAR equations [13,14], often leading to the identification of compounds with increased potency. QSAR equations have provided direction for improving selectivity of action and deciding when to terminate a compound series. Through QSAR-based series design more information per compound synthesized can be obtained, thus leading to increased efficiency [13]. A new characterization of bioisosterism using QSAR has broadened the use of this principle and its utility in drug design. Also, QSAR results have contributed to our understanding of the mechanism of action of drugs and provided information on the nature of enzyme-ligand and drug receptor binding sites. A discussion of these various aspects follows.

\section{HYDROPHOBICITY IN A QSAR CONTEXT}

Prior to 1964, an appreciation of the magnitude of the role of hydrophobicity in drug action in SAR studies by medicinal chemists was quite limited. For example, a chloro substituent was usually thought of exclusively in terms of its electron-withdrawing properties and it was not until the advent of QSAR that its hydrophobic properties were adequately considered. The importance of hydrophobicity in controlling drug action is illustrated by Table 1, which was compiled from a collection of some 98 QSAR equations, evenly divided between in vitro and in vivo examples, taken from Reference 10. The hydrophobic parameter is the major variable in ca. two thirds of the in vivo cases and over $40 \%$ of the in vitro examples. Also, Hansch has reported [15] that in a database of some 3000 biological QSARs only 15\% lack a term for hydrophobicity. 
<smiles>[R]C(=O)N([R7])O</smiles>

(1)<smiles>Oc1c(Br)cc2c(c1Br)CCO2</smiles>

(2)

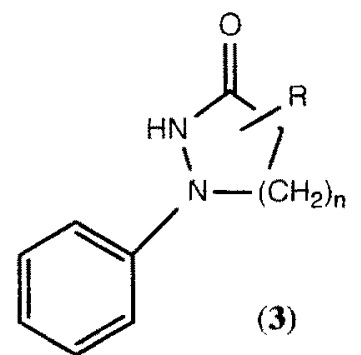

(3)

\section{Accounting for relative potency in a series}

Accounting for relative potency in a series is illustrated by some recent publications on 5-lipoxygenase inhibitors. Summers et al. [16] found that for a series of 111 structurally diverse hydroxamic acids of general structure (1) the predominant property determining the inhibitory potency is the hydrophobicity of the molecule. Hydrophobicity in this compound series spans seven $\log$ units and compound potencies differ by more than four orders of magnitude. Based on the hydrophobic parameter coefficient of 0.57 it was concluded that these compounds appear to be partially desolvated on binding to 5-lipoxygenase (a slope of one indicates complete desolvation) which suggests [17] that the inhibitor rests upon a surface or shallow trough of the enzyme. This also illustrates how QSAR can provide insight into the nature of enzyme-ligand sites.

A similar case was reported by Hammond et al. [18] for a series of some fifty 4- and 6substituted 2,3-dihydro-5-benzofuranol 5-lipoxygenase inhibitors (2) where a linear dependence of $\log \mathrm{IC}_{50}$ on $\log \mathrm{P}$ extends over three orders of magnitude in biological activity and five orders of magnitude in partition coefficient.

A third study by Hlasta et al. [19] on a series of 1-phenyl-3-pyrazolidinones and related tetrahydropyridazinones (3) showed a relationship of increased 5-lipoxygenase inhibitory potency with an increase in $\log \mathrm{P}$ and an $\mathrm{N}$-phenyl electronic effect as measured by a ${ }^{13} \mathrm{C}$ NMR chemical shift parameter, e.g. Eq. 3:

$$
\begin{aligned}
& \mathrm{pIC}_{50}=0.90( \pm 0.19) \log \mathrm{P}+0.15( \pm 0.06) \mathrm{C} \mathrm{NMR} 1-24.19( \pm 8.67) \\
& \mathrm{n}=21, \mathrm{r}^{2}=0.79, \mathrm{~s}=0.49, \mathrm{~F}(2,18)=33.6, \mathrm{p}=0.001
\end{aligned}
$$

Independently, $\log \mathrm{P}$ explains about $70 \%$ of the $\mathrm{pIC}_{50}$ data variance, thus making hydrophobicity

TABLE 1

\begin{tabular}{|c|c|c|c|c|c|c|}
\hline \multirow[t]{2}{*}{ Parameter } & \multicolumn{3}{|c|}{ In vitro frequency $(\%)$} & \multicolumn{3}{|c|}{ In vivo frequency $(\%)$} \\
\hline & Total & Major var. & Sole var. & Total & Major var. & Sole var. \\
\hline Hydrophobic (all) & 69 & 42 & 16 & 88 & 64 & 29 \\
\hline Hydrophobic (parabolic) & 20 & & & 63 & & \\
\hline Electronic & 65 & 27 & 8 & 57 & 18 & 0 \\
\hline Steric & 29 & 15 & 6 & 24 & 6 & 2 \\
\hline Other & 20 & 4 & 4 & 18 & 6 & 4 \\
\hline
\end{tabular}

PARAMETER FREQUENCY IN REGRESSION EQUATIONS 
the dominant parameter controlling relative activity as in the other two series of lipoxygenase inhibitors.

\section{Tissue selectivity}

An example of the relationship of hydrophobicity to tissue selectivity is provided in a recent study by Roth et al. [20] on a series of HMG-CoA reductase inhibitors which are an important class of drugs for lowering plasma total and LDL-cholesterol in hypercholesterolemic patients. It has been proposed [21] that the side effects of these drugs may be reduced by confining their action to the liver and that tissue selectivity is dependent on hydrophobicity with the more hydrophilic compounds showing higher liver selectivity. This hypothesis was tested by comparing a set of 15 potent substructurally diverse inhibitors encompassing a broad range of calculated hydrophobicity (C LOGP) for their ability to inhibit sterol synthesis in tissue cubes derived from rat liver, spleen and testis. A linear relationship was found between tissue/liver ratios and $\log P$ as expressed in Eqs. 4 and 5:

$$
\begin{aligned}
& \log \left(\mathrm{IC}_{50} \text { spleen/liver }\right)=0.93-0.52 \mathrm{C} \text { LOGP } \\
& \mathrm{n}=14, \mathrm{r}^{2}=0.62, \mathrm{~s}=0.65, \mathrm{~F}=21.6(\mathrm{p}<0.001) \\
& \log \left(\mathrm{IC}_{50} \text { testis/liver }\right)=1.17-0.65 \mathrm{C} \text { LOGP } \\
& \mathrm{n}=15, \mathrm{r}^{2}=0.67, \mathrm{~s}=0.75, \mathrm{~F}=26.2(\mathrm{p}<0.001)
\end{aligned}
$$

Although about one third of the data variance is not accounted for in both of these equations, suggesting that factors other than hydrophobicity related to differences between the compounds are also involved, there is, nevertheless, a strong statistical correlation between tissue selectivity and $\log \mathrm{P}$. These equations show that at C LOGP $=2$ there is no selectivity between liver and the other tissues. Below a C LOGP of 2 the compounds are increasingly liver selective as they become more hydrophilic; above a C LOGP of 2 selectivity for testis and spleen increases with increasing hydrophobicity. Since intrinsic potency differences amongst the inhibitors were minimal, it was concluded that tissue selectivity was highly dependent on the ability of peripheral tissues to discriminate between compounds on the basis of hydrophobicity.

\section{Central nervous system penetration}

An early result from the QSAR studies of Hansch was the finding [22] that maximum potency in 16 sets of hypnotics was obtained for compounds with a $\log P$ value $\left(\log P_{o}\right)$ of around 2 . This was associated with transport properties and penetration of the blood brain barrier by passive diffusion, controlled by the hydrophobicity of the compounds. The implications for drug design were quickly noted both for CNS agents and for avoidance of CNS side effects in other types of drugs. The general concept of a $\log \mathrm{P}_{\mathrm{o}}$ optimum of 2 for CNS penetration was supported by later findings on anesthetics [23], benzodiazepines [24] and centrally acting antihypertensive agents [25]. However, it was also recognized that some small hydrophilic molecules use an active transport process and that molecular size can have a significant negative effect for MW $>500$ [26].

In 1987 Hansch et al. reported [27] on studies covering the partition coefficients of a wide range of clinically used CNS drugs, including barbiturates, benzodiazepines, antipsychotics, antidepressants and other miscellaneous types. These generally fell into a range of $1.5-2.5$ when measured 


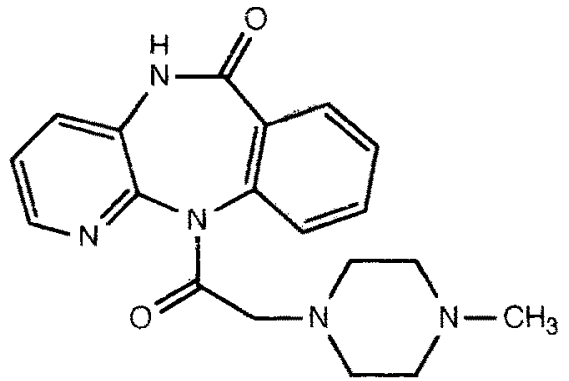

(4)

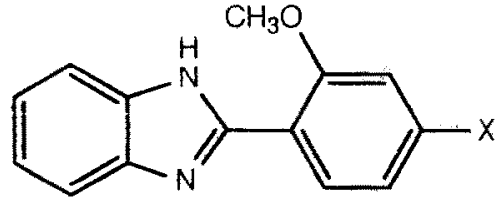

(5)

at $\mathrm{pH} 7.4$ (distribution coefficient), consistent with the earlier concept. Although there were some significant outliers, suboptimal CNS penetration can be compensated for by a larger dose. It appears that charged molecules which are large and hydrophobic can passively diffuse through the blood brain barrier. Usually the presence of such a charge is thought to preclude passage through this barrier.

Avoidance or marked reduction of CNS effects should in principle be achievable with $\log P$ values outside the range 1.0-3.0, based on the parabolic relationship of CNS entry and $\log$ P. A variety of antihistamines were examined in this context [27] and it was observed that the nonsedating antihistamines had $\log \mathrm{P}$ values at $\mathrm{pH} 7.4$ well outside this range, in contrast to the highly sedative diphenhydramine which has a $\log \mathrm{P}$ of $1.76(\mathrm{pH}$ 7.4). Terfenadine and loratadine, both classified as nonsedating, may be examples of antihistamines with very low CNS entry because of their highly hydrophobic nature ( $\log \mathrm{P}$ values of $>4.00$ and 5.37 , respectively at $\mathrm{pH} 7.4$ ).

Pirenzepine (4) is an antiulcer agent with overall structural features that resemble the tricyclic psychotropic drugs. However, it has a $\log \mathrm{P}$ of $-0.64(\mathrm{pH} 7.4)$ and consequently is devoid of CNS side effects [28]. A promising cardiotonic drug ARL $57\left(\mathbf{5}, \mathrm{X}=\mathrm{OCH}_{3}\right)$ with a $\log \mathrm{P}$ of $2.59(\mathrm{pH}$ 8) had to be abandoned because of CNS-related side effects in humans. However, replacement of an $-\mathrm{OCH}_{3}$ group by $-\mathrm{SOCH}_{3}\left(\mathrm{ARL} 115\right.$, sulmazole; $\mathbf{5}, \mathrm{X}=\mathrm{SOCH}_{3}$ ) reduced the $\log \mathrm{P}$ to 1.17 $(\mathrm{pH} 8)$, while maintaining adequate cardiotonic properties with virtual elimination of the CNSrelated side effects [29].

Lovastatin and simvastatin, HMG-CoA reductase inhibitors in clinical use for hypercholesterolemia with $\log \mathrm{Ps}(\mathrm{pH} 7)$ of 1.70 and 2.06 respectively, have both been observed to cause significant reduction in the duration of sleep in some patients while pravastatin $(\log \mathrm{P}=-0.23$ at pH 7) had no effect on sleep patterns [30]. This represents yet another example of the same phenomenon which can be used to advantage in drug design.

An interesting study by Young et al. [31], published in 1988 on the design of centrally acting $\mathrm{H}_{2}$ receptor antagonists, showed an excellent correlation of $\log$ brain/blood concentration ratios in rat and the partition parameter, $\Delta \log \mathrm{P}$, defined as $\log \mathrm{P}_{\text {oct }}-\log \mathrm{P}_{\text {cyclohexane, for a group of six }}$ compounds consisting of the three brain-penetrating drugs clonidine, mepyramine and imipramine, and three typical $\mathrm{H}_{2}$ receptor antagonists. On the other hand, there was no correlation with $\log \mathrm{P}_{\text {oct }}$ for the neutral compounds. The result was interpreted as suggesting that brain penetration is increased by lowering the overall hydrogen-bonding ability of a compound, which enhances its ability to cross cell membranes. The study was subsequently expanded to cover 20 structurally diverse compounds which confirmed the initial results. One of the compounds, zolantidine (SK\&F 95282) was identified for use in studying histaminergic $\mathrm{H}_{2}$ receptor mechanisms in brain. 
A subsequent study of this concept by Van de Waterbeemd and Kansy [32] on the same two compound sets showed that it is only necessary to measure $\log \mathrm{P}$ in an alkane solvent and that a first estimate of brain penetration can even be obtained from calculated hydrophilic and hydrophobic surface contributions of the molecules. Clearly, further investigation of $\Delta \log P$ in relation to $\mathrm{CNS}$ penetration is warranted.

\section{Pharmacokinetic considerations}

A successful drug candidate must have favorable pharmacokinetic properties relating to absorption, distribution, metabolism and excretion, which all have hydrophobicity as a critical determining factor. Such relationships have been examined in a QSAR context for many series of compounds and have been reviewed by Austel and Kutter [33] and by Lien [34]. Absorption from the gastrointestinal tract generally shows a parabolic relationship with $\log P$ and an optimal range for $\log \mathrm{P}$ (or $\log \mathrm{D}$ for ionizable compounds) of $0.5-2.0$. For buccal and percutaneous absorption the optimum $\log \mathrm{P}$ is much higher. The optimum hydrophobicity for distribution of a drug to many parts of the body may be at a $\log \mathrm{P}$ of around 2 [35]. Metabolism by microsomal oxidation tends to increase with $\log \mathrm{P}$, although this is somewhat series dependent. Protein binding is positively correlated with $\log \mathrm{P}$ in a linear form, often up to $\log \mathrm{P}$ values of 3 or higher. Hydrophilic compounds with molecular weight less than 500 tend to undergo fairly rapid renal excretion and have a short duration of action.

Sometimes QSAR studies can identify an area of a molecule that is not important for the desired pharmacological activity. This area can then be used to modify the pharmacokinetic or physicochemical properties, such as solubility, without impacting activity. An example is provided by a QSAR analysis of a series of fifty-six 8-phenylxanthines which were of interest as adenosine antagonists [36]. The resulting QSAR showed that potency was relatively insensitive to changes in the para position of the phenyl substituent. On this basis an additional 20 compounds were synthesized that contained mostly para substituents, designed to increase aqueous solubility. These were highly potent receptor binders, as predicted by the QSAR, and aqueous solubility was dramatically increased.

\section{General considerations}

The $\log \mathrm{P}_{\mathrm{o}}$ value obtained from QSAR studies has proved to be useful in providing drug design concepts and has already been discussed in this article with regard to CNS penetration and drug absorption. Early in the development of QSAR, $\log \mathrm{P}_{\mathrm{o}}$ values were shown to be much lower for activity against gram-negative compared to gram-positive bacteria, which is consistent with the observation that the gram-negative cell wall contains more lipid and hence may be relatively more effective in slowing down the passage of highly lipophilic molecules [37]. Of importance in antitumor drug design [38] is that $\log \mathrm{P}_{\mathrm{o}}$ can be expected to be quite different for different tumor types, e.g. $\log \mathrm{P}_{\mathrm{o}}=0$ for $\mathrm{N}$-nitrosoureas against ascitic tumors, whereas solid tumors such as Walker 256 respond to more lipophilic drugs with a $\log P_{\circ}$ of about 2.

In correlations of drug potency in whole animals the $\log \mathrm{P}$ term reflects a composite of various processes such as absorption, distribution, protein binding, metabolism, excretion and hydrophobic bonding at the target receptor. The $\log \mathrm{P}_{\mathrm{o}}$ value for each compound series will differ, depending on the relative importance of all these processes.

In drug discovery projects involving in vitro test systems, e.g. enzyme inhibitors, it is important 

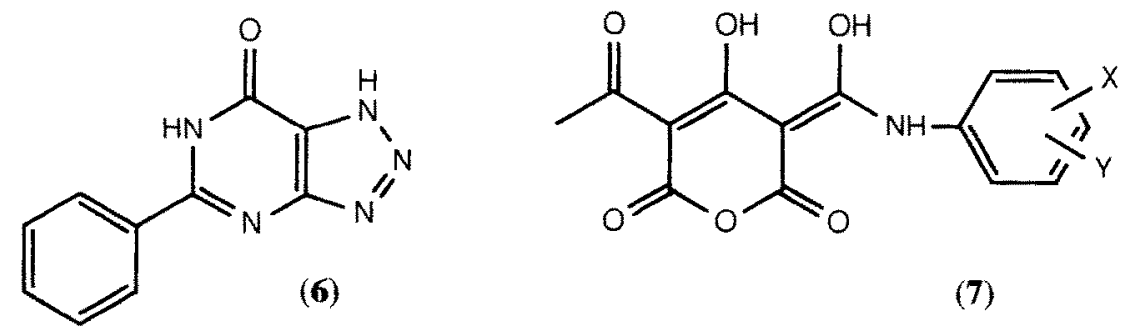

(7)

not to pursue potency increases in a compound series to very high levels through large increases in hydrophobicity, which can often be achieved when there is a large hydrophobic binding pocket. This might result in compound $\log \mathrm{P}$ values well above the range necessary for optimal in vivo activity. Also the advantages of keeping drug hydrophobicity to the lowest value consistent with achieving the necessary drug effectiveness and property profile has been discussed by Hansch who pointed out that toxicity tends to increase as drugs become more hydrophobic [27].

\section{POTENCY OPTIMIZATION}

Impressive examples of the use of QSAR in dramatically increasing potency in a series have been reported by Wooldridge [39] for a series of 2-phenyl-8-azapurin-6-ones (6) and by Cramer [40] for a series of pyranenamines (7), both relating to antiallergic activity as measured by rat PCA activity. These have been reviewed in detail elsewhere [41] and involve potency enhancements of up to 1000 -fold, extending far beyond the substituent space spanned (SSS) in the initial QSAR relationships. Features of the Wooldridge studies are the identification of a clinically active compound, M\&B 22,948 (zaprinast), intermingling of QSAR and traditional medicinalchemistry approaches and the projection of the results to structures completely different from those which formed the basis of the QSAR studies. Noteworthy aspects of the Cramer work are the productive use of a simple graphical data/parameter display as well as regression analysis in identifying the key requirements for increased potency (greater hydrophilicity and a zero electronic effect) which were not obvious, justification for the synthesis of a compound with a novel hydrophilic substituent $\left(7 ; \mathrm{X}, \mathrm{Y}=3,5-\mathrm{NHCOCH}(\mathrm{OH}) \mathrm{CH}_{2} \mathrm{OH}\right)$ which was the most potent in a series of 98 compounds, and a series member $\left(X=3-\mathrm{NH}_{2}, \mathrm{Y}=4-\mathrm{OH}\right)$ which entered clinical trials. Both compound series require very hydrophilic compounds for maximum potency, which might have more general implications for this type of activity.

A more recent example was described by de Paulis et al. [42] where a QSAR analysis resulted in the design and synthesis of a new 10 -fold more active derivative $\left(\mathbf{8} ; \mathrm{R}_{2}=\mathrm{R}_{3}=\mathrm{OCH}_{3}, \mathrm{R}_{5}=\mathrm{Br}\right.$,

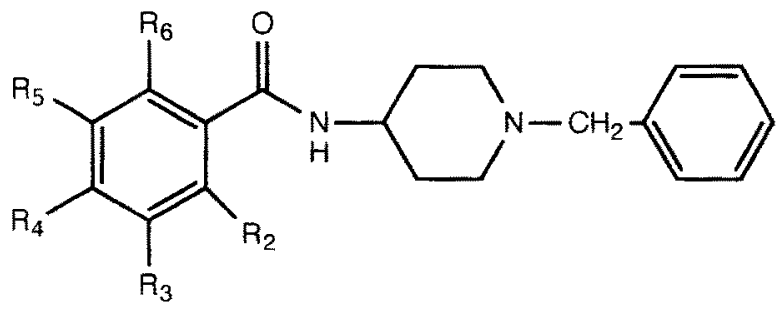


$\left.\mathrm{R}_{6}=\mathrm{OH}\right)$ in a series of antidopaminergic $N$-(1-benzyl-4-piperidinyl)salicylamides. Increased potency, as measured by affinity for the $\left[{ }^{3} \mathrm{H}\right]$ spiperone binding site, was correlated with electron release into the salicylamide ring from positions 3,4 and 5 as parametrized by the Swain-Lupton resonance constant $\mathrm{R}$ and the presence of a 6-OH substituent. Again, in this example the successful prediction of increased potency extended far beyond the SSS of the compound set on which the QSAR was formulated. Generally the predictive reliability of QSARs under these circumstances is not high, but the three examples described show that the testing of such predictions can be very rewarding. They also illustrate a great strength of classical QSAR, in that correlations with physicochemical parameters can be easily interpreted and successfully extrapolated in the design of new compounds. In contrast, the interpretation and use of correlations involving nonphysicochemical parameters (e.g. molecular connectivity indices) is generally much more difficult.

\section{BIOISOSTERISM}

Bioisosterism has long been used by medicinal chemists in drug design in exploring the effect of substituting one atom or grouping for another in a lead compound. It has been defined in a QSAR context by Hansch $[12,43]$. If in a particular series activity is solely dependent on $\pi$, then any two substituents with very similar $\pi$ values will be bioisosteric. If both $\pi$ and $\sigma$ (or $F$ and $R$ ) control activity, then groups for which these values are essentially the same are considered to be bioisosteric. In the case where $\pi, \sigma$ and $\mathrm{E}_{\mathrm{s}}$ all have a role in activity determination, the two groups are considered to be bioisosteric if all of the parameter values match.

In a very recent application [44] this concept of bioisosterism provided the impetus for the novel replacement of a chloro substituent $(\pi=0.71, \mathrm{~F}=0.41, \mathrm{R}=-0.15$ ) by a 1-pyrrolyl substituent $(\pi=0.95, \mathrm{~F}=0.50, \mathrm{R}=-0.09$ ) in an antihypertensive AII receptor antagonist lead series (9) with retention of activity. This led to the synthesis of a closely related compound ( 9 , $\mathrm{X}=2$-trifluoroacetyl-[1-pyrrolyl]) (CI-996) which was selected for preclinical development.

In addition to parameter values representing hydrophobic, electronic and steric effects, other physicochemical properties can also be considered in bioisosteric replacements. Durant et al. [45] noted a close similarity in the physicochemical properties of cyanoguanidines and thioureas in terms of N-C-N geometry, acidity, hydrophobicity and conformer interconversion energies. This formed the basis of the thiourea group replacement in the $\mathrm{H}_{2}$-antagonist compound metiamide, which had encountered toxicity problems, by a cyanoguanidine group, resulting in the breakthrough drug cimetidine.

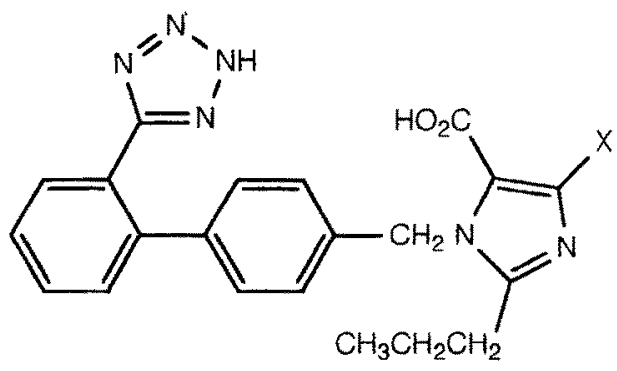

(9)

$$
\mathbf{X}=\mathbf{C I}
$$

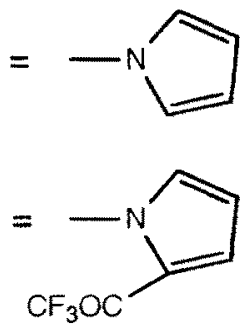

CI-996 


\section{MECHANISTIC INSIGHTS}

The fact that QSAR is based on readily understandable physicochemical phenomena often permits useful mechanistic insights. Tute [46] has termed this the diagnostic value of Hansch analysis. Well-known examples are the antifungal drug griseofulvin, where a QSAR analysis of analogs suggested that activity may depend on the reactivity of the enone system with a receptor nucleophile [47], and the tuberculostatic drug isoniazid where QSAR studies supported quaternization of the pyridine nitrogen as the rate-determining step in the mechanism of antibacterial action [48]. Also in a recent study of antiinflammatory diclofenac analogs [49], inhibition of cyclooxygenase activity and adjuvant-induced arthritis in rats were similarly correlated with hydrophobicity and the twist angle between the two phenyl rings as the critical parameter controlling activity, which is supportive of cyclooxygenase inhibition as the underlying mechanism for the antiinflammatory activity of the compounds.

\section{SYNTHESIS TERMINATION}

One of the most difficult decisions a medicinal chemist faces is when to terminate synthesis in a series. QSAR can be helpful in this respect. For example, for a nine-membered series of nitrogen mustard anticancer agents [50] QSAR equations derived for activity and toxicity were identical and so there is no realistic prospect of significant selectivity improvement in the series. A similar situation existed for a series of anticancer triazines [51], where both activity and toxicity correlated with a $-\sigma$ term. QSAR studies have also provided a convincing rationale for terminating synthesis in series of anticancer anthracyclines [52], anticancer colchicines [53], antiinflammatory agents [54], antibacterial triazines [55], erythromycin analogs [56] and xanthine adenosine antagonists [36].

\section{RECEPTOR MAPPING}

Information on receptor sites and the nature of receptor-ligand interactions can be deduced from QSAR studies. This can be most readily accomplished with enzymes, sometimes in conjunction with X-ray crystallographic studies and molecular graphics [57]. An extensively investigated and well-reviewed subject has been the enzyme dihydrofolate reductase (DHFR), inhibitors of which have been the source of antibacterial, antimalarial and antineoplastic agents. A recent publication reported the use of QSAR equations for bacterial and avian DHFR to calculate selectivity indices for trimethoprim, tetroxoprim and two other specially designed 2,4-diamino-5(substituted-benzyl)pyrimidines, reflecting subtle enzyme-binding differences revealed by the QSAR studies [58].

A QSAR study of the binding of a series of N1-substituted 5-aryl-2,4-dioxopyrimidines (10) to thymidylate synthase supported the presence of both a cationic binding site and a hydrophobic region and in addition revealed an unusual reversal of electronic requirements for binding and catalysis [59]. QSAR equations formulated for the inhibition of HSV1 and HSV2 thymidine kinases by a series of $N$-phenylguanines (11) have provided insight into the nature of inhibitor binding sites for both enzymes. For compounds with meta substituents on the phenyl ring, binding of both enzymes is due to a combination of hydrophobic and electrostatic interactions, the electrostatic contribution having greater relative importance in HSV2 TK. Also, it could be 

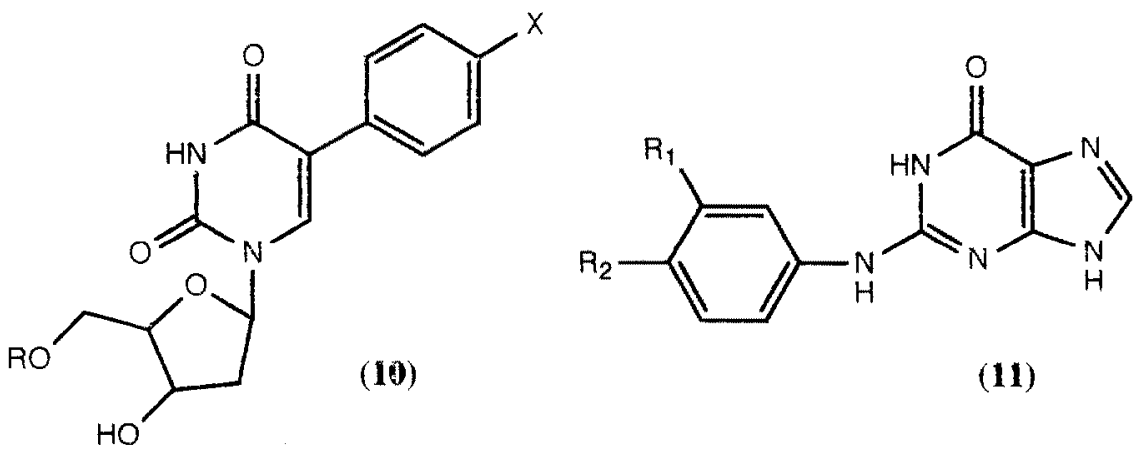

(11)

deduced that the space into which the para substituents fit is electrostatic in nature and possibly hydrophilic [60]. The receptor mapping of $\mathrm{N} 1$ substituents of quinolone antibacterials using a combination of QSAR and molecular modeling studies has been recently reported. In this model, compounds mispredicted by previous QSAR studies are accounted for [61]. A variety of nonenzyme receptor models have also been constructed based on QSAR studies. These models can be very useful in guiding synthetic efforts in the search for improved compounds.

\section{EXAMPLES OF THE FREE-WILSON APPROACH}

The Free-Wilson method (usually implemented as the Fujita-Ban modification) has been employed far less frequently than the Hansch method, primarily because the derived de novo constants give no indication of which physicochemical property or combination of properties is controlling activity and therefore the results cannot be projected to new substituents. However, the method has yielded some useful results, as illustrated by two recent examples.

In an analysis of the analgesic potency of some 50 semisynthetic opioid narcotics, a satisfactory correlation was obtained only by assuming interdependent contributions of substituents at two positions. The correlation enabled the potency of five substituted compounds to be predicted and subsequent testing showed these predictions to be accurate. A further analysis, in which phenolic compounds were considered separately from the ethers, allowed the conclusion that if both phenolic and nonphenolic members of the series act on the same receptor, they must bind at different subsites or in alternate modes [62].

A series of 36 dipeptoid antagonists of the CCK-B receptor was analyzed by considering the compounds as composed of three regions; the $\mathrm{N}$-terminus, variants on the tryptophan moiety and the C-terminus. A highly significant correlation was found, accounting for $97 \%$ of the data variance, which suggested that the three domains of the compounds independently contribute to binding affinity and are thus additive in receptor binding affinity effects. It was calculated that substitution of $D-\alpha$-methyltryptophan for L-tryptophan increases the free energy of binding by $3.5 \mathrm{kcal} \mathrm{mol}^{-1}$ which is explained by a 300 -fold difference in conformational entropy between these two analogs [63].

\section{THE ROLE OF QSAR IN THE DESIGN OF MARKETED DRUGS AND LATE-STAGE DRUG CANDIDATES}

One measure of the impact of classical QSAR is its role in the design of compounds which reach 
<smiles>CCn1cc(C(=O)O)c(=O)c2cc(F)c(N3CCNCC3)cc21</smiles>

(12)

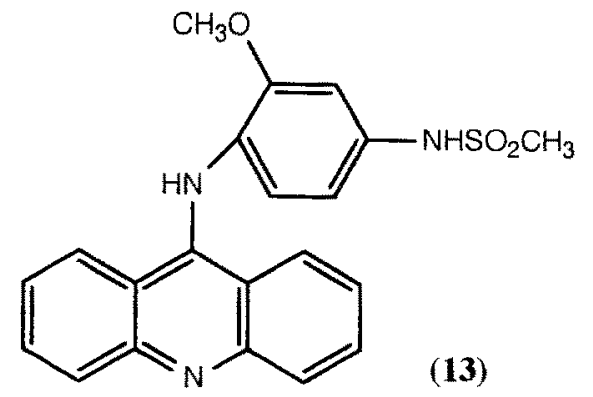

a late investigational stage or are marketed. A brief mention of some examples of these follows.

Quinolones are an important class of antibacterial agents. The research efforts of Koga [64] in this field to develop new improved drugs made extensive use of QSAR and culminated in the design of norfloxacin (12), now an important and well-established marketed drug. A detailed review of this work has been provided by Fujita [41].

A comprehensive program on the design and synthesis of over 700 acridines (DNA binders) as potential anticancer agents in which QSAR studies played an important role was carried out at the Cancer Chemotherapy Research Laboratory in Auckland, New Zealand, by Atwell et al. who very early in their investigations recognized the importance of relative hydrophobicity [65]. A QSAR relationship on 509 acridines was formulated with a $\log \mathrm{P}=-0.6$, which is consistent with that for other antileukemic drugs. The outcome of this research was the selection of the compound $m$-AMSA for clinical trials, which is now marketed as the drug amsacrine (13).

The use of a nonstatistical operational scheme [5] was reported in the design of 3-amino-1benzylpyrazolin-5-ones, a class of potent high-ceiling diuretics [66]. This work resulted in the development of muzolimine (14) which is now a marketed drug.

Cimetidine (15) is a highly successful antiulcer drug and its design from metiamide has been described in the section on bioisosterism. Since the rationale for its synthesis involved a quantitative comparison of physicochemical properties, it qualifies for inclusion here under a broad definition of classical QSAR.

An account of two allergy drugs which reached the clinical-trial phase, zaprinast and a pyranenamine, in which QSAR studies featured prominently, has been given in the section on potency optimization. Also, the key role of QSAR in the discovery of the cardiotonic drug sulmazole, which underwent clinical trials, was described (vide supra).

The QSAR-directed design of a nondepressive cardioselective $\beta$-blocker which reached the clinical-investigation stage, RS-51288, containing a novel endobicyclo[3.1.0] hexylethyl (EBHE) side chain, has been reported by Unger [67]. Fujita [41] has given detailed reviews of several

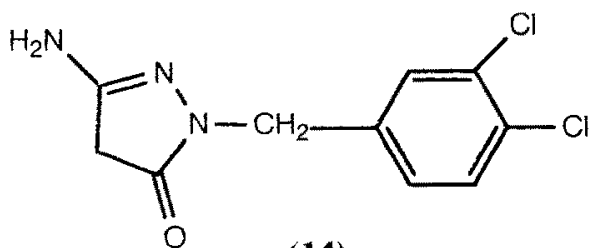

(14)

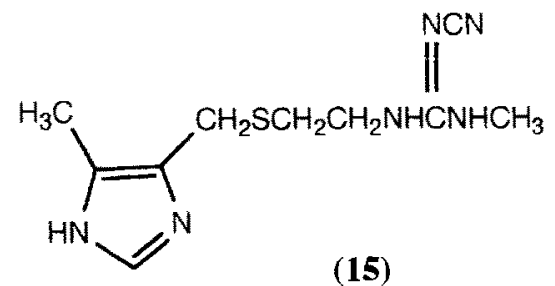

(15) 
QSAR-driven design projects which yielded compounds reaching advanced stages of investigation. These were a benzodiphenylmethylpiperazine cerebral vasodilator, KB-2796, which entered clinical studies, a 4-anilinopyrimidine antidepressant, RS-2232, a quinazoline antihypertensive, MY-5561, and a furoindolecarboxamide with analgesic/antiinflammatory activity, all of which reached an advanced preclinical stage of investigation. As previously discussed under Bioisosterism, the AII antagonist antihypertensive CI-996, arising from a novel bioisosteric replacement, was selected for preclinical development.

\section{SOME INTERESTING RECENT QSAR STUDIES}

A novel concept was developed as a result of studies on antineoplastic agents in multidrug resistance, which illustrates how QSAR can stimulate new thinking. It was found that crossresistance of actinomycin-D-resistant Chinese hamster cells was enhanced by both the increased size and hydrophobicity of the antitumor agent. Preliminary studies with methotrexate-resistant L 1210 cells indicated that cross-resistance is increased in the case of moderate-sized hydrophilic drugs. As a result of these and other studies it was concluded that current chemotherapy regimens may be improved by treating resistant cells with antineoplastic agents displaying physicochemical characteristics opposite to those of the original inducing agent [68].

In the first reported successful QSAR analysis involving in vivo activity of a compound against solid tumors, Schnurr et al. [69] reported the synthesis and QSAR analysis of a series of guanidinothiazole carboxamides (16) which show significant systemic activity for survival enhancement of mice with established micrometastatic disease of 3LL Lewis lung carcinoma. Optimal correlations were found in the case of 5- and 6-substitution between the probit transform of the druginduced increased lifespan (ILS) and electronic and hydrophobic parameters. No correlations were found for 4-substitution. In general, activity increased with increased hydrophobicity but, judging by the parameter coefficients, the electron-withdrawing effect of a substituent had a greater influence on activity. The optimum hydrophobicity for the series appeared to be above the range encompassed by the analogs reported in the study. As discussed by the authors, there are limitations and advantages to this type of QSAR study. A limitation is the time and expense required to adequately quantify the biological data for all the compounds in the study with the in vivo antitumor testing requiring a minimum of 10-20 days. Also, the analogs must be relatively homogeneous with regard to other pharmacologic and metabolic properties, in addition to possessing significant antitumor effects. However, the developing QSAR was useful in formulating the synthetic strategy leading to the discovery of the optimal analogs as well as indicating where an empirical approach was best. The end result was the discovery of a number of promising

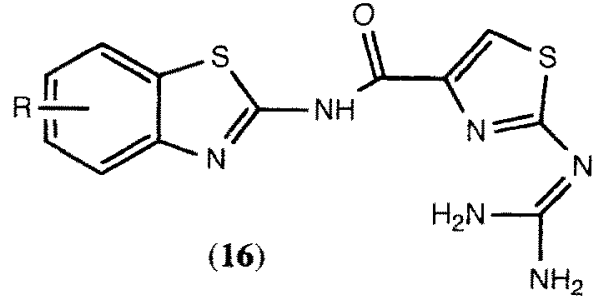

(16)

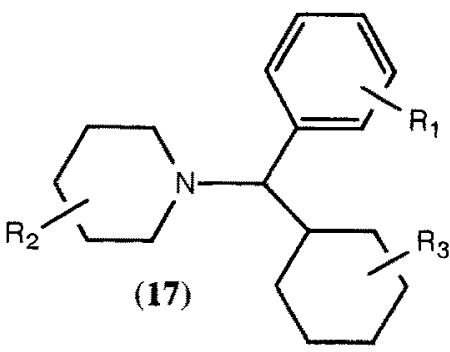




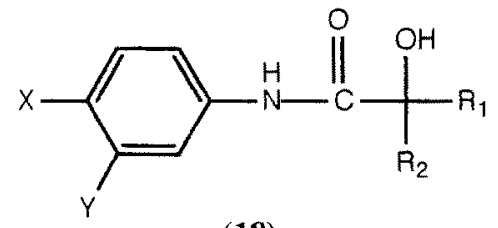

(18)

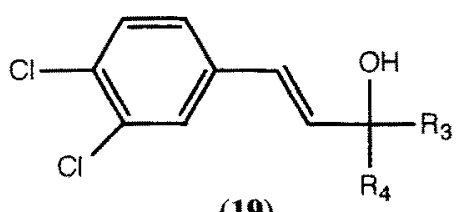

(19)

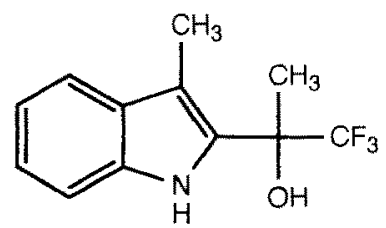

(20)

compounds, exemplified by $16, \mathrm{R}=5-\mathrm{F}$, with substantial efficacy in the clinically predictive model of $3 \mathrm{LL}$ Lewis lung carcinoma.

The first QSAR analysis accounting for the variation in activity of phencyclidine (PCP) derivatives (17), expressed as receptor binding activity, has been reported [70]. This result was also unusual in that the activity of the series of 24 compounds was well correlated $(r=0.913)$, with a single parameter representing the difference in direction of the dipole vector. This was interpreted in terms of the favorable effects on activity of the complementarity of charge densities around the molecule and the receptor cavity, with the dipole-moment term representing the electrostatic distribution of the molecule.

A report by Morris et al. [71] on the design of some novel nonsteroidal antiandrogens nicely illustrates yet another way in which the quantitative correlation of biological activity with physicochemical properties can be put to effective use in drug design, through the unraveling of the essential factors governing activity. This study on the physicochemical requirements for antiandrogenic activity in a series of 2-hydroxypropionanilides (18) showed that a single dominant conformation has an important influence on the ability of the - $\mathrm{OH}$ group to act as a hydrogenbond donor. The strength of the hydrogen bond to an external acceptor was shown to be an important factor controlling the biological activity of the compounds. These and other physicochemical parameters were then used in the design of structurally novel antiandrogens $(\mathbf{1 9}, \mathbf{2 0})$ which exhibited the anticipated activity.

\section{CONCLUDING OBSERVATIONS}

The utility and scope of classical QSAR in many facets of drug design has been amply demonstrated in the three decades since its inception. During this time it has passed through various stages: method development, exploration of applications, user overenthusiasm followed by skepticism, to a point where its strengths, limitations and the types of problems to which it might be fruitfully employed are well understood.

As with any approach, certain limitations must be recognized which for classical QSAR include the need to discern the molecular properties that control activity and to express these in parameter form, the inadequate treatment of three-dimensional aspects, and restricted applicability beyond the confines of a cogeneric series. However, QSAR is readily comprehended and relatively easy to use, since the principles on which it is based are very familiar to medicinal chemists. Therefore, in the realm of drug design methodology it frequently has a favorable benefit/resource investment relationship.

Classical QSAR has been successfully integrated with molecular graphics and molecular modeling and very recently [72] with the Comparative Molecular Field Analysis (CoMFA) methodol- 
ogy. Hansch [35] has commented on an increasing future emphasis on the lateral validation of QSAR, i.e. placing a new QSAR into a matrix of structure-activity relationships which are selfconsistent both from the point of view of physicochemical parameters and basic biochemistry. Classical QSAR is solidly established as a core methodology and over the next decade we can expect further refinements, interfacing with other drug design approaches, and diverse productive applications to drug design problems.

\section{REFERENCES}

1 Hansch, C. and Fujita, T., J. Am. Chem. Soc., 86 (1964) 1616.

2 Free Jr., S.M. and Wilson, J.W., J. Med. Chem., 7 (1964) 395.

3 Fujita, T. and Ban, T., J. Med. Chem., 14 (1971) 148.

4 Kubinyi, H. and Kehrhahn, O.-H., J. Med. Chem, 19 (1976) 578.

5 Topliss, J.G., J. Med. Chem., 15 (1972) 1006.

6 Topliss, J.G., J. Med. Chem., 20 (1977) 463.

7 Martin, Y.C., Quantitative Drug Design, Marcel Dekker, New York, NY, 1978.

8 Franke, R., Theoretical Drug Design Methods, Elsevier, Amsterdam, 1984.

9 Ramsden, C.A. (Ed.) Comprehensive Medicinal Chemistry, Vol. 4, Pergamon Press, New York, NY, 1990.

10 Topliss, J.G. (Ed.) Quantitative Structure-Activity Relationships of Drugs, Academic Press, New York, NY, 1983.

11 Kubinyi, H., In Jucker, E. (Ed.) Progress in Drug Research, Vol. 23, Birkhauser Verlag, Basel, 1979, pp. 97-198.

12 Hansch, C., Drug Dev. Res., 1 (1981) 267.

13 Martin, Y.C., J. Med. Chem., 24 (1981) 229.

14 Hopfinger, A.J., J. Med. Chem., 28 (1985) 1133.

15 Hansch, C., Acc. Chem. Res., 26 (1993) 147.

16 Summers, J.B., Kim, K.H., Mazdiyasni, H., Holms, J.H., Ratajczyk, J.D., Stewart, A.O., Dyer, R.D. and Carter, G.W., J. Med. Chem., 33 (1990) 992.

17 Hansch, C. and Klein, T.E., Acc. Chem. Res., 19 (1986) 392.

18 Hammond, M.L., Kopka, I.E., Zambias, R.A., Caldwell, C.G., Boger, J., Baker, F., Bach, T., Luell, S. and Macintyre, D.E., J. Med. Chem., 32 (1989) 1006.

19 Hlasta, D.J., Casey, F.B., Ferguson, E.W., Gangell, S.J., Heimann, M.R., Jaeger, E.P., Kullnig, R.K. and Gordon, R.J., J. Med. Chem., 34 (1991) 1560.

20 Roth, B.D., Bocan, T.M.A., Blankley, C.J., Chuckolowski, A.W., Creger, P.L., Creswell, M.W., Ferguson, E., Newton, R.S., O'Brien, P., Picard, J.A., Roark, W.H., Sekerke, C.S., Sliskovic, D.R. and Wilson, M.W., J. Med. Chem., 34 (1991) 466.

21 Mahoney, E.M., In Abstracts of the Xth International Symposium on Drug Affecting Lipid Metabolism, Houston, TX, 1989, p. 103.

22 Hansch, C., Steward, A.R., Anderson, S.M. and Bentley, D.L., J. Med. Chem., 11 (1968) 1.

23 Glave, W.R. and Hansch, C., J. Pharm. Sci., 61 (1972) 589.

24 Biagi, G.L., Barbaro, A.M., Guerra, M.C., Babbini, M., Bartoletti, M. and Borea, P.A., J. Med. Chem., 23 (1980) 193.

25 Timmermans, P.B.M.W., Brands, A. and Van Swieten, N.S., Arch. Pharm., 300 (1977) 217.

26 Levin, V.J., J. Med. Chem., 23 (1980) 682.

27 Hansch, C., Björkroth, J.P. and Leo, A., J. Pharm. Sci., 76 (1987) 663.

28 Eberlein, W., Schmidt, G., Reuter, A. and Kutter, E., Arzneim.-Forsch./Drug Res., 27 (1977) 256.

29 Hansch, C., Drug Inf. J., 18 (1984) 115.

30 Serajuddin, A.T.M., Ranadive, S.A. and Mahoney, E.M., J. Pharm. Sci., 80 (1991) 830.

31 Young, R.C., Mitchell, R.C., Brown, T.H., Ganellin, C.R., Griffiths, R., Jones, M., Rana, K.K., Saunders, D., Smith, I.R., Sore, N.E. and Wilks, T.J., J. Med. Chem., 31 (1988) 656.

32 Van de Waterbeemd, H, and Kansy, M, Chimia, 46 (1992) 299.

33 Austel, V. and Kutter, E., In Topliss, J.G. (Ed.) Quantitative Structure-Activity Relationships of Drugs, Academic Press, New York, NY, 1983, pp. 437-496. 
34 Lien, E.J., Annu. Rev. Pharmacol. Toxicol., 21 (1981) 31.

35 Hansch, C., In Wermuth, C.G. (Ed.) Medicinal Chemistry for the 21st Century, Blackwell Scientific Publications, Oxford, 1992, p. 292.

36 Hamilton, H.W., Ortwine, D.F., Worth, D.F., Badger, E.W., Bristol, J.A., Bruns, R.F., Haleen, S.J. and Steffen, R.P., J. Med. Chem., 11 (1985) 1071.

37 Lien, E.J., Hansch, C. and Anderson, S.M., J. Med. Chem., 11 (1968) 430.

38 Dunn III, W.J., In Topliss, J.G. (Ed.) Quantitative Structure-Activity Relationships of Drugs, Academic Press, New York, NY, 1983, p. 173.

39 Wooldridge, K.R.H., In Temple, D.L. (Ed.) Drugs Affecting the Respiratory system, American Chemical Society, Washington, DC, 1980, pp. 117-123.

40 Cramer III, R.D., Snader, K.M., Willis, C.R., Chakrin, L.W., Thomas, J. and Sutton, B.M., J. Med. Chem., 22 (1979) 714.

41 Fujita, T., In Ramsden, C.A. (Ed.) Comprehensive Medicinal Chemistry, Vol. 4, Pergamon Press, New York, NY, 1990 , pp. 540-544.

42 De Paulis, T., Hall, H., Kumar, Y., Rämsby, S., Ögren, S.O. and Högberg, T., Eur. J. Med. Chem., 25 (1990) 507.

43 Hansch, C., J. Med. Chem., 19 (1976) 1.

44 Sircar, I., Hodges, J.C., Quinn III, J., Bunker, A.M., Winters, R.T., Edmunds, J.J., Kostlan, C.R., Conolly, C., Hamby, J.M., Topliss, J.G., Keiser, J.A. and Panek, R.L., J. Med. Chem., 36 (1993) 2253.

45 Durant, G.J., Emmett, J.C., Ganellin, C.R., Miles, P.D., Parsons, M.E., Prain, H.D. and White, G.R., J. Med. Chem., 20 (1977) 901.

46 Tute, M.S., In Harper, N.J. and Simmonds, A.B. (Eds.) Advances in Drug Research, Vol. 6, Academic Press, London, 1971, pp. 10-11.

47 Hansch, C. and Lien, E.J., J. Med. Chem., 14 (1971) 653.

48 Seydel, J.K., Schaper, K.J., Wempe, E. and Cordes, H.P., J. Med. Chem., 19 (1976) 483.

49 Moser, P., Sallman, A. and Wiesenberg, I., J. Med. Chem., 33 (1990) 2358.

50 a. Lien, E.J. and Tong, G.L., Cancer Chemother. Rep., Part 1, 57 (1973) 251.

b. Andrews, A.W., Leo, A., Panthananickal, A., Hansch, C., Theiss, J. and Shimkin, N., J. Med. Chem., 24 (1981) 859.

51 Callejas, S.S., Dunn III, W.J. and Greenberg, J., J. Med. Chem., 19 (1976) 1299.

52 Fink, S.I., Hansch, C., Leo, A., Jamakawa, M. and Quin, F., Farmaco, Ed. Sci., 35 (1980) 965.

53 Beisler, J.A. and Quinn, F.R., J. Med. Chem., 24 (1981) 251.

54 Gund, P. and Jensen, N.P., In Topliss, J.G. (Ed.) Quantitative Structure-Activity Relationships of Drugs, Academic Press, New York, NY, 1983, p. 324.

55 Tute, N.S., In Topliss, J.G. (Ed.) Quantitative Structure-Activity Relationships of Drugs, Academic Press, New York, NY, 1983, pp. 51-52.

56 Martin, Y.C. and Fischer, E.W., In Topliss, J.G. (Ed.) Quantitative Structure-Activity Relationships of Drugs, Academic Press, New York, NY, 1983, pp. 91-92.

57 Hansch, C. and Klein, T.E., Methods Enzymol., 202 (1991) 512.

58 Selassie, C.D., Li, R.-L., Poe, M. and Hansch, C., J. Med. Chem., 34 (1991) 46.

59 Chang, G., Schwepler, D., Decedue, C.J., Balzarini, J., De Clercq, E. and Mertes, M.P., J. Med. Chem., 31 (1988) 1141.

60 Gambino, J., Focher, F., Hildebrand, C., Maga, G., Noonan, T., Spadori, S. and Wright, G., J. Med. Chem., 35 (1992) 2979.

61 Ohta, M. and Koga, H., J. Med. Chem., 34 (1991) 131.

62 Hernández-Gallegos and Lehmann, F.P.A., J. Med. Chem., 33 (1990) 2813.

63 Higginbottom, M., Kleen, C. and Ratcliffe, G.S., J. Med. Chem., 35 (1992) 1572.

64 a. Koga, H., Itoh, A., Murayama, S., Suzue, S. and Irikura, T., J. Med. Chem., 23 (1980) 1358.

b. Koga, H., In Fujita, T. (Ed.) Structure-Activity Relationships; Application to Drug Design and Mode-of-Action Studies, Nankodo, Tokyo, 1982, p. 177.

c. Fujita, T., In Jolles, G. and Wooldridge, K.R.H. (Eds.) Drug Design: Fact or Fantasy, Academic Press, New York, NY, 1984, pp. 19-25.

65 Atwell, G.J., Denny, W.A., Cain, B.F., Hansch, C., Panthananickal, A. and Leo, A., J. Med. Chem., 25 (1982) 276.

66 Horstmann, H., Möller, E., Wehinger, E. and Meng, K., In Cragoe Jr., E.J. (Ed.) Diuretic Agents, ACS Symposium 
Series, Vol. 83, American Chemical Society, Washington, DC, 1978, p. 125.

67 Unger, S.H., In Topliss, J.G. (Ed.) Quantitative Structure-Activity Relationships of Drugs, Academic Press, New York, NY, 1983, pp. 190-193.

68 Selassie, C.D., Hansch, C. and Khwaja, T.A., J. Med. Chem., 33 (1990) 1914.

69 Schnurr, R.C., Gallaschum, R.J., Singleton, D.H., Grissom, M., Sloan, D.E., Goodwin, P., McNiff, P.A., Fliri, A.F.J., Mangano, F.M., Olson, T.H. and Pollock, V.A., J. Med. Chem., 34 (1991) 1975.

70 Inami, Y., Tomita, T. and Terada, Y., Chem. Pharm. Bull., 39 (1991) 1426.

71 Morris, J.J., Hughes, L.R., Glen, A.T. and Taylor, P.J., J. Med. Chem., 34 (1991) 447.

72 McFarland, J.W., J. Med. Chem., 35 (1992) 2543. 